\title{
A question of universality: inclusive education and the principle of respect
}

\author{
Ruth Cigman
}

\section{Introduction}

Inclusive education is a contested concept. Some reserve it for the principle that mainstream schools should welcome and adapt themselves to all children without exception, irrespective of the nature or severity of their difficulties or disabilities. Others use it to refer to the principle that such schools should welcome and adapt themselves to all children as far as possible. The second principle embraces the thought that mainstream schools are incompatible with an adequate education for some children; the first principle rejects this thought.

I shall call these principles universalist and moderate respectively, and describe their defendants as universal and moderate inclusionists. Moderates see inclusive education as compatible with, and indeed as requiring, the existence of 'special schools' for a small number of children. Universalists tend to be antagonistic to such schools, seeing them as threatening the project of universal inclusion. At the heart of this conflict of views is disagreement about what is 'possible'. The universalist says or implies that it is 'possible' to include everyone; the moderate denies this. I shall call this the 'possibility clause'.

It has been suggested that the dispute is a storm in a tea-cup. It is about the placement of a tiny minority of children, and an onlooker might ask: why should it matter what kinds of schools they attend, so long as their basic educational needs are met? This might be answered, initially, by pointing out that in a world of scarce resources, the meeting of educational needs raises tough questions about distributive justice. Society cannot afford to give everyone what they want, and the ambition to give everyone what they need is scuppered by the considerable conceptual difficulty of identifying needs and comparing severity of need. These abstract-sounding problems translate into daily nightmares for children, parents and teachers who live with the practical reality of what they see as educational misplacement. The inclusion debate is hugely consequential for many individuals, even if they are a small proportion of those involved in education. This is one reason why the disagreement between universalists and moderates is not a storm in a tea cup. 
But there is another reason. The inclusion debate is not only about the education of children; it is also, as I shall argue in this paper, about the nature of a decent society. Decent societies, according to Avishai Margalit (1996), are ones "whose institutions do not humiliate people (p. 1)." I intend to follow this definition, and will suggest that, to the extent that special schools or other institutions are both systematically humiliating and generally tolerated, the decency of the society to which they belong is impugned. 'Humiliation' is defined by Margalit as "any behaviour or condition that constitutes a sound reason for a person to consider his or her selfrespect injured (ibid, p. 2).” He distinguishes between psychological or empirical ascriptions of humiliation (a person, or group, feels humiliated, as a matter of fact) and normative ascriptions of humiliation (a person, or group, has a sound reason to feel humiliated).

This distinction is of the first importance. The claim under consideration is that special schools are inherently, or by their nature, humiliating or demeaning for the children who attend them. They give children a 'sound reason' to consider their self-respect injured, even if they do not in fact feel this way. The claim is not, I should add, typically expressed this way, but it is implied by statements like the following (Centre for Studies in Inclusive Education, 2004):

The discrimination inherent in segregated schooling offends the human dignity of the child... Segregated schooling appeases the human tendency to negatively label and isolate those perceived as different. It gives legal reinforcement and consolidation to a deeply embedded, self-fulfilling, social process of de-valuing and distancing others on the basis of appearance and ability in order to consolidate a sense of normality and status.

The CSIE argues that special schools should be phased out altogether. The implication is that we should ignore the wealth of testimony from people who place great value on special schools: testimony from parents of children with disabilities, and also from many disabled people themselves. Jim Sinclair, an autistic man, writes:

I do not know of any advocate from within the disability community who believes that inclusion should not be an available option. Disability advocates believe that disabled people should be able to go anywhere and do anything in mainstream society... However there are concerns within the disability community that inclusion is not always the best option for every person with every disability, and that involuntary inclusion is as problematic as involuntary segregation (Sinclair, 1998a). 
Against such testimony, the CSIE suggests that, insofar as we retain and tolerate the institutions known as special schools, we are sustaining a practice that is fundamentally indecent. Is this right? Do special schools as such, simply because they are special schools, and not because (or insofar as) they are bad or unsuccessful special schools, give children a sound reason to consider their self-respect injured?

Some will no doubt object that this question over-intellectualises the problem. It seeks for reasons for feelings, and as such flies in the face of an influential tradition that puts reasons (or justifications) in one category, and feelings (or emotions) in another. This tradition, which is firmly rooted in contemporary culture, advocates a kind of unconditional respect for feelings whatever they may be, independently of questions of justification. Indeed, the idea of seeking to justify feelings is seen as issuing from a set of unpleasant attitudes that are censorious and 'judgemental'.

This approach is embodied in the modern 'self-help' movement, which seeks to boost the self-esteem of children independently of the bases or reasons that one might have for experiencing a sense of self-esteem. I have written about this at length elsewhere (Cigman, 2004). I want to illustrate the point about sounds reasons for humiliation by reference to the possible excesses of feminism.

Feminists, traditionally, are angry with men. They feel humiliated by their treatment and status in male-dominated societies. Under certain circumstances, these feelings (anger, humiliation) are not only feelings; they are reasonable responses to the situations in which women find themselves. It is essential to emphasise this 'reasonableness', which paves the way for a potent critique of the social conditions which oppress women.

However feelings of anger or humiliation can become inappropriate or excessive, depending on the adjustments that society makes or fails to make. Without going into any detail (which might provoke unnecessary disagreement), feelings can outlive the rationale that initially inspired them. This, I want to emphasise, is not a political but a conceptual point. The point is that it is possible for feelings to be excessive or unreasonable insofar as they fail to respond to circumstantial change. This possibility lies at the heart of Margalit's distinction between psychological and normative ascriptions of humiliation.

The idea that special schools are inherently humiliating or demeaning is often (but by no means always) advanced by people who experienced the pain and 
humiliation of old-style segregated education. There is no doubt that the legacy of such schools for many is an enduring sense of stigma and inferiority. The principle of such schools, established by the 1944 Education Act, was that 'abnormal' or 'handicapped' children would be sent to an institution which catered for one of eleven categories of handicap, irrespective of any other attributes that the child may have. Although some children fared reasonably within this system (on the liberal aspect of the 1944 Act see Dyson and Slee, 2001), many suffered intensely from the experience of being reduced to a category of handicap. It should be clear a) that many children had sound reasons to feel humiliated and demeaned within this system, and b) that this is sufficient reason to abolish such institutions. This, I believe, was recognised and addressed in the 1981 Education Act which followed the 1978 Warnock Report.

Universalists say or imply that special schools in the late $20^{\text {th }} /$ early $21^{\text {st }}$ century are in principle the same as post-1944 segregated schools. They are inherently demeaning and should therefore be abolished, and the implication is that special school attendance can only be voluntary in the limited sense that it is chosen from options available within an indecent society. It is chosen (and can only be chosen) insofar as mainstream schools do not provide a non-humiliating educational experience for some children; do not, in other words, adapt themselves adequately to those who fail to conform to a narrow stereotype of 'normality'.

Associated with this claim is an argument about so-called labels: terms which refer to types or categories of difficulty or disability, like 'autistic', 'deaf', 'learning difficulty', and so on. The suggestion is that such 'labels' are conceptually humiliating in the same sense as that in which special schools are institutionally humiliating. (This is implied in the CSIE passage quoted above, where 'labelling' is associated with negativity, devaluation and distancing.) Conceptual and institutional humiliation are analogous - they involve alleged injuries to self-respect — and also, of course, they are socially linked in the sense that 'labels' are associated with choice of special school, or within-school special provision. My question about 'labels' parallels my question about special schools: do 'labels' as such constitute a sound reason to consider one's self-respect injured? As with special schools, some people with disabilities and difficulties accept and even value a 'label', claiming that it brings access to educational resources, greater understanding from others, and so on. There is an autistic pride movement called Autscape, which considers itself radical rather than regressive, and argues that the condition known as autism is seen as 
embarrassing or shameful because it is misunderstood and misrepresented in society. 'Say it loud, autistic and proud' is the label-affirming title of a newspaper article on this subject (Burne, 2005). Jim Sinclair, quoted above, writes:

I am not a 'person with autism'. I am an autistic person... Saying 'person with autism' suggests that autism is something bad - so bad that it isn't even consistent with being a person. Nobody objects to using adjectives to refer to characteristics of a person that are considered positive or neutral (Sinclair 1998b).

Are we to ignore this view? Are we to accept the universalist idea that the 'labelling' of disabilities and difficulties is essentially negative or humiliating? Len Barton (1993, p. 31) suggests as much when he assumes a continuity between special educational 'labelling' and the negative 'labelling' of children in the old secondary modern schools as 'thick', 'stupid, 'hopeless'. Is 'autistic' like 'thick'? Does a child have a sound reason to feel humiliated solely because he or she is identified as autistic?

It is crucial to raise these questions. They involve a departure from purely empirical or psychological questions about whether people do feel humiliated by special school attendance or 'labels'. Empirically, one thing is certain; some do and some do not feel humiliated by these things. It would be interesting to discover the true proportions of this difference amongst the so-called disabled population (and of course the boundaries of this group are ragged to say the least) as a whole. As far as I am aware, this empirical question has never been properly investigated. Meanwhile universalists talk as if they represent all disabled people when they talk about the reduced self-respect and self-esteem suffered by children in special schools. They support this assumption by retaining the expression 'segregated schooling' to emphasise the continuity between special schools as they are today and post-1944 segregated schooling.

Empirically they are wrong; they do not represent all disabled people, as the Autscape movement makes clear. Disabled people speak with many voices, exactly as one would expect. Indeed one could argue that the idea of a 'disabled voice'which appears not infrequently in the literature-disrespectfully implies that independent thinking is alien to this group. 
However my present concern is not this. I want to explore the philosophical or conceptual question of whether there are 'sound reasons' for a person to consider her self-respect injured by a) special school attendance or b) disability 'labelling', as such.

\section{Self-respect and the goals of inclusion}

What counts as a sound reason to consider one's self-respect injured? I am suggesting that this abstract-sounding question has an urgent claim to our attention because it informs the puzzlement and unease that many people feel when they consider the universalist argument. The universalist characterises special schools and 'labels' as inherently demeaning without clearly explaining why this must be so. There is an empirical argument (some people feel demeaned by special schools/'labels'), which (as I argued) disregards the multiple voices on this matter. There is a rights argument (all children without exception have a right to a mainstream education: see UNESCO 1994), which fails to identify a source for this right beyond the fact that it is claimed (see Cigman, 2007). The rights argument sometimes sounds like a duty argument, suggesting that all parents have a duty to send their children to a mainstream school, irrespective of the nature or severity of the child's difficulties or disabilities. Another duty argument is sometimes ascribed to schools, which are said to have a duty to provide an appropriate educational environment for every child without exception. In all this talk (or implied talk) of duties, there are suggestions about what 'ought' to be the case without any apparent awareness of the fact that, as philosophers put it, 'ought implies can'. (This principle is often attributed to Kant, though he did not say it in so many words.) Schools 'ought' to provide a satisfactory environment for every child; but can they? Is it possible to do what universalists say schools ought to do? Many parents whose children have struggled in inclusively oriented mainstream schools seriously doubt that this is so.

Many special school attendees are there voluntarily, and indeed many have struggled to gain resources to go there. It would ordinarily make a crucial difference to the pride and self-respect of children whether they attend an institution because they have been denied access to another, or whether they have elected (indeed struggled) to go there. Segregated schooling post-1944 involved the former; children with so-called handicaps were simply refused entry to mainstream schools. Of course the same can be true today, and if so there may be a case to be answered. However 
contemporary exclusions are generally couched (and by law must be couched) in terms of the practical difficulties of educating children with widely disparate needs and abilities together. These alleged practical difficulties are typically viewed with scorn by universalists, or written off as due to under-funding or under-commitment to inclusion. It is this that many find puzzling, not least because it appears to remove the need to investigate the practical issues empirically.

To return to our question, what constitutes a sound reason for a person to consider her self-respect injured? At this point, I shall offer only a summary answer, to be developed in the course of this paper. The basic answer, I believe, was given by Kant, whose moral philosophy is considered by most philosophers today to articulate the foundation of modern liberal thinking. Kant thought that the proper object of respect is the moral will, meaning the capacity possessed by all or most human beings to reflect rationally on what is right and wrong, distinguishing this from what one desires. Irrespective of the kind of life a person leads, there is a presumption of capacity to reflect in such a way, which constitutes the foundation of our belief that every human being (with the obvious exception of those who are comatose and the like) is entitled to self-respect. There is no space in this paper to expound this grand idea in any detail, but I would like to suggest that it relates to our topic in the following way.

First, Kant provides a basis for the notion of moral responsibility: the freedom to commit oneself to the values one passionately believes in and in particular to control one's vital interests. Of course this freedom is not unconditional. It may be limited by available resources and by the requirements of distributive justice. Nonetheless, it is arguable that the closure of special schools would infringe upon this freedom in serious ways. Many parents choose special schools because their children have been miserable and unable to learn in mainstream ones. Such parents often deny, after bitter experience, that it is possible for mainstream schools to adapt satisfactorily to the needs of their child. If respect is to be shown to parents who struggle for the retention of special schools, their capacity to reflect responsibly about the vital interests of their children must be taken seriously.

Second, Kant identified a kind of treatment of human beings which is not to be tolerated. This is the treatment of a human being purely as a means to other people's ends, as in slavery or the sexual abuse of women. To treat a human being purely as a means to an end is to fail to respect him or her in the most fundamental way possible. 
Something like this is hinted at when universalists to talk as though all children are required to attend mainstream schools, irrespective of whether or not this serves their own interests. The CSIE, for example, claims:

The existence of 'special' schools contributes to the insecurity and fear of rejection by those in the mainstream (undated).

No evidence is given of this. Nor are we told whether special schools are supposed to contribute to the insecurity and fear of rejection of all, most or just a few. The failure to address this and other empirical questions contributes to the air of rhetoric which often surrounds the universalist position. There is the worrying implication that parents have a duty to avoid sending their children to special schools in order to protect the feelings of children other than their own, and irrespective of the difficulties experienced by their own children in mainstream schools. This suggests that parents of children who are already vulnerable in all sorts of ways have a duty, in Kantian terms, to treat their children as means to the ends of other children's wellbeing.

It is widely believed that Kant's moral theory was not so much a model or conjecture as an articulation of the structure of our thinking about morality. If this is right, it goes some way towards explaining why many feel uneasy about universalism. I have argued that universalism:

aspires towards a society in which all children attend mainstream schools, but it is based on an understanding of what special schools mean which is conspicuously unshared (Cigman 2007).

In other words, universalists tend to disregard the fact that special schools are seen by many parents, not as inherently demeaning environments, but as liberating and in the best sense educational environments for their children. Many parents fight for their children to attend special schools, and a parental attack on Tony Blair over the widespread closure of special schools in the UK was headline news just a few years ago. No universalist can be unaware of this passionate clash of convictions, yet the universalist tendency is to portray special schools as inherently demeaning, as though there were no plausible view other than their own. The goal of universal inclusion is 
pursued in a way that is pointedly (and, one might say, disrespectfully) oblivious of the non-universality of its own values.

In short, a person has a sound reason to consider her self-respect injured if a) she is denied the freedom to pursue and control her vital interests, and/or b) she is treated as a means to other people's ends. This, as I said, is a basic answer to the question about when humiliation is and is not a justified feeling. We now need to consider and develop this answer in relation to inclusive education.

\section{3) Inclusion and the concept of possibility}

As a theory about the educational practices that ought to be adopted, universalism flounders on the notion of possibility. Ought implies can; it is either meaningless or unjust to say that someone (or an institution) ought to do something that in a real sense she (it) cannot do. Whether all children can satisfactorily be educated in the same classrooms and with the same curricula (which is what the inclusive philosophy is often said to amount to) depends in a serious way on empirical matters, about which I shall have more to say in due course. (It also depends in a serious way on the conceptual question of what counts as a 'satisfactory education'; but I shall not discuss this here.) But first I want to avert a possible misunderstanding arising out of my argument so far.

I have suggested that universalism provokes unease by stating or implying a) that parents who believe passionately in special schools for their children should be rebutted or ignored, and $b$ ) that some children may be used as means to the end of other children's well-being. These two implications raise worrying questions about the extent to which the universalist agenda upholds the principle of respect. Having said this, however, I think it is important to bring out the sense in which all inclusionists, universalist and moderate, are concerned about the principle of respect. I see the philosophy of inclusion, and the heated debate to which it has given rise, as a sustained attempt to resolve problematic questions about respect to which the recent history of educational segregation has given rise.

Who is different from whom? To what extent should we conceptualise difference? To what extent should we treat everyone as the same? Is it demeaning to be identified as different from the norm? If we retain the concept of normality, how should we define it and how should we think about people who fall outside its bounds? If we reject the concept of normality, how can we ensure that atypical needs 
are adequately met? How might we be failing those whose needs are atypical? In particular - and I see this concern as pervasive and shared - how might we be failing to respect them?

The inclusion debate, according to the argument of this paper, is a kind of conversation in which these and similar questions are picked over. The universalist exhibits what I call a homogenising tendency, meaning a reluctance to conceptualise individual differences and a desire to talk instead about human diversity as the condition of which we are all a part. The moderate, on the other hand, exhibits a distinguishing tendency, which draws attention to individual differences (and particularly individual needs), in part as a corrective to the homogenising tendency of the universalist. The homogenising and distinguishing tendencies gain their impetus, respectively, from the motives a) to ensure that everyone has access to common social goods and b) to protect individuals from neglect of their needs.

Both these motives arise out of a concern with self-respect and the avoidance of humiliation. Developing the Kantian account of respect, Margalit offers two interconnected concepts of humiliation. The first:

I claim that humiliation is the rejection of a human being from the 'Family of Man'...that is, treating humans as nonhuman, or relating to humans as if they were not human. Treating persons as if they were not human is treating them as if they were objects or animals. (1994, p. 108)

And the second:

There seems to be a competing notion of humiliation to that of rejection from human society. This is the notion of humiliation as the deliberate infliction of utter loss and control over one's vital interests. (Ibid, p. 115)

It seems clear that the universalist preoccupation with inclusion expresses concern about humiliation in the first of Margalit's senses: humiliation as rejection from the 'Family of Man'. Schools are institutions which prepare children for adult life as a fully paid up member of society. The testimony of many adults who were excluded from mainstream schools in the 1950s and 60s expresses the lasting pain and humiliation of being socially marginalised. However my question remains: are special school attendees necessarily marginalised, and thus understandably humiliated, in a comparable way? Or is the attempt to deny them access to such 
schools a way of humiliating them (denying them self-respect) by denying them control over their vital interests?

That universal respect is the fundamental issue that concerns all inclusionists is confirmed again and again in the literature. Mel Ainscow, a well known universalist, writes:

[Teachers must] ...overcome the dangers and limitations of deficit thinking: only in this way can we be sure that pupils who experience difficulties in learning can be treated with respect and viewed as potentially active and capable learners. (Clark et al 1998, pp. 11 -12)

The reference to deficit thinking belongs to an argument about the use of 'labels' ('labels' fix a negative image on to children, and encourage people to see them as 'deficient'), with which some will disagree. However, we see from this passage that there is a fundamental concern: all children without exception should be treated with respect. People may disagree about what it means to show or withhold respect, but that all human beings are entitled to unconditional respect is, I suggest, the basic concern driving this debate.

Universalists locate respect and disrespect primarily within institutions and concepts. Moderates are concerned about forms of disrespect within inclusive (i.e. basically respectful) institutions, and identify this in part with the withholding of distinguishing concepts which give children access to the differential provision that they may urgently want and need. 'Exclusion within inclusion' was a central concern of Mary Warnock in her 2005 paper, where she led the way for the moderates by arguing that many children with disabilities and difficulties suffer from feelings of exclusion within inclusive schools (Warnock 2005, p. 45; see also Rogers, 2007 and Pirrie and Head, 2007). Such children are often bullied, teased or shunned. They may have sensory or other difficulties which mean that they need an environment unlike that of a typical mainstream school. (This seems to be true particularly of autistic children.) Whereas in primary schools these sorts of difficulties are often easily overcome - primary school children are usually amenable to new ways of thinking about difference, and may be easily encouraged to put aside initial prejudices - in secondary schools life can be extremely hard for children who do not conform to standards set by their peers. It seems that as children grow older, differences become 
more consequential, and the pain of a child who is stubbornly perceived as different may be irresolvable, except by removal to another school.

Although Warnock does not articulate as I have the principle of respect for all children, it seems to me that her concern about 'exclusion within inclusion' is fundamentally this. To say 'this child is thoroughly miserable and failing to learn' without even considering the possibility that the child needs a different kind of school is, she implies, disrespectful. It is humiliating to feel excluded by other children at the school one attends, and this resembles the way it is humiliating to be excluded from the school one wants to attend.

The universalist is unmoved by these sorts of considerations, and it is an interesting question why this is so. I have suggested that institutional and conceptual respect are the universalist's first concerns, and that these are bound up with the idea of a decent society. But can a society be decent if it tolerates exclusion within institutions? Is Warnock right to suggest (as I think she implies) that such exclusion is humiliating and hence an injury to one's self-respect? It is in response to this kind of question that the possibility clause is required: even if some children feel excluded within inclusive institutions, it is possible that they should become included. It is possible, that is, that they will come to enjoy the goods of mainstream education: the sense of belonging to a community, the right to participate in shared programmes of learning, the opportunity to prepare for adult life in an inclusive society, and so on.

The possibility clause is essential, for without it there is an unavoidable sense that the suffering of some children is shamefully ignored. The universalist does not think he ignores this. He sees suffering as an inevitable but provisional corollary of the 'process of inclusion', as Mike Oliver explains when he says that inclusion “is not a thing that can be delivered by politicians, policy-makers or educators, but a process of struggle that has to be joined (1996, p. 90)." 'Process of struggle' implies that some failure is inevitable; the answer is not to duck it but to engage with it. This is not a matter of keeping children in mainstream schools knowing that it is impossible that they should ever benefit; it is a matter, on the contrary, of believing that they can benefit, and trying to ensure that they do so.

This is seductive thinking. It suggests that even to ask whether the suffering of a child might be unacceptable is to fall into the trap of assuming that inclusion is a 'thing that can be delivered', and hence assessable as a 'bad thing'. It gags parents who have a sense that their children are needed for the project of inclusion, whether or 
not their children need inclusive schools. Conceptually, this way of thinking relies on a notion of possibility which is tenuous and weak. What do we mean when we insist that something is possible? Usually we mean that there are empirical grounds for feeling confident that a certain thing might happen. When I set off on my hill walk, I was sure that a full day's walking was impossible, given the recent injury to my foot. It is now $4 \mathrm{pm}$ and, given that my foot is holding up well, I now believe it is possible for me to finish the course. This, I suggest, is an everyday use of the word 'possible', and it is empirically based.

The universalist has no empirical basis for the possibility clause. He does not say: we used to have doubts, but inclusive practice has improved so much that children we used to be concerned about are now learning happily alongside everyone else. Rather, the possibility of including everyone is asserted or assumed, and in this sense it is essentially an article of faith. It is asserted, moreover, in the face of a great deal of evidence to the contrary, showing that some children not only are unhappy in mainstream schools, but seem destined to remain so given our growing understanding of the nature of their difficulties. (See, for example, Sainsbury, 2000, and Rogers, 2007a.) The moderate rejection of the possibility clause is based on precisely this kind of evidence; but the universalist is, as I said, curiously unmoved.

The assertion that it is possible to include every child in the mainstream appeals to a notion of possibility which is rather like a double negative: it is not impossible. We think in this way when we say, for example, that it is possible that two adults produced by sperm from the same donor might one day meet and fall in love. We are not willing to deny that this is possible; but statistically (given safeguards) it is almost vanishingly improbable. The universalist's possibility clause is not statistical; as I said, it is more like an article of faith. As such it is unable to support a sincere belief in the possibility of including all children without provoking profound, and understandable, doubts.

The refusal to deny that all children can be included is maintained in the face of considerable empirical evidence. I have mentioned autistic children, and the literature on children with social and emotional difficulties supports the idea that mainstream schools can be disastrous not only for their teachers and classmates, but for these children themselves (see Rogers 2007b). It is hardly surprising that this is so when one thinks about the meaning of mainstream education as a creative community of children embodying shared values and a shared approach to learning. Some 
children have difficulties which are inescapably social in nature; they appear unable to understand the nature of groups or to participate in such communities (see Moore 2007). The idea that they can learn to participate - that such learning is 'possible' (see Cigman, 2001) — may be optimistic without being remotely realistic.

It is hardly surprising that the universalist drains the notion of possibility of empirical or factual content, given her uneasy relationship (as I shall argue) with human, everyday reality. The reserve about the conceptualisation of difference, though intended to yield a richer perception of the reality of diversity, in fact creates a fatal barrier against proper receptivity to, and respect for, individual children. This will be the theme of the next section, where I shall explore the theoretical underpinning of the universalist position.

\section{Inclusive education and the concept of reality}

The universalist sees special schools as inherently demeaning, meaning that even if a child does not actually feel demeaned in a special school, she has reason to do so. This point is emphasised using terms like 'exclusion' and 'segregation' to refer to special school practice. Children at special schools are excluded, are segregated, even if they have elected to attend these schools and are confident and learning well.

This view has a theoretical or metaphysical underpinning, which is to say that it will be found compelling or not depending on whether one is prepared to accept a highly abstract argument. Many do accept this argument, and I would add sceptically that many accept it hook, line and sinker, meaning that they are insufficiently critical and accept something they do not properly understand. Indeed I would go so far as to say that it is not possible properly to understand this argument in the way that it is typically presented.

This is a large subject, for I am talking about the need to have a metadiscussion about the sociological assumptions at the heart of much special education. In the space available, I can do no more than touch on this subject, and no doubt my comments will be found inadequate by many.

The universalist position is said to be supported theoretically by a paradigm that is known as post-positivist. The post-positivist paradigm negates the positivist paradigm which says:

1. Differences between learners are "objectively "real"". 
2. These differences "take the form of deficits and difficulties" which may be understood through medicine and educational psychology.

3. Special education is essentially a "rational response to these difficulties and deficits" (Clark et al, p. 158).

This paradigm will be recognised as that which informed post-1944 segregated education. Some people were seen as normal; others had deficits and difficulties ('handicaps'). Such deficits and difficulties were seen as objectively 'real' and susceptible to medical and/or psychological interventions. The aim of special education was to respond rationally to them, which meant giving priority to medical and/or psychological issues.

Post-1944 segregated education was unsatisfactory in ways that are familiar. Most unsatisfactory was the fact that many children were systematically humiliated by being reduced to a category of handicap. We have discussed how they were excluded from the 'Family of Man', i.e. socially marginalised, in ways that were unjust and unacceptable.

However positivism was not, according to proponents of post-positivism, confined to the post-1944 era. The 1981 Act, which followed the 1978 Warnock Report and brought large numbers of children with (what were now called) special needs into mainstream schools, was said to perpetuate positivist ideas about differences between children. It retained the idea that there are 'normal' and 'abnormal' children. It tried to address the needs of the latter group through medical and psychological interventions. It retained the idea that schools are primarily for 'normal' children, bringing in others almost as an afterthought and insofar as they did not interfere with the education of the 'normal' ones. Theoretically or metaphysically, it is argued, the post-Warnock educational era retained the three positivist assumptions listed above.

The shift from positivism to post-positivism in the 1990s was accompanied by the conceptual shift from thinking in terms of integration to thinking in terms of inclusion. To integrate children (as Warnock proposed) is to bring together children whose difference in kind is not in question. (Differences between learners are assumed to be objectively 'real'.) To include children in single institutions is to give up the idea that there are differences of kind independently of socially constructed differences. It is to make the concept of diversity more fundamental than the concept 
of difference, and this is expressed by saying that differences between learners are 'objectively unreal'.

The post-positivist paradigm negates the positivist paradigm as black negates white. At the heart of this paradigm shift is a pair of abstract claims:

- Differences between learners are objectively 'real'.

- Differences between learners are objectively 'unreal'.

On the face of it, these express two different beliefs or opinions that a person may hold. 'Do I believe that differences between learners are objectively real or unreal?' sounds like a question that any intelligent person may ask herself and, after some reflection, answer. We could then line up the adherents of one claim opposite the adherents of the other, extracting from each a substantial position. However this is precisely what we cannot do. Because it is so unclear what the assertion and denial really mean or amount to, the opportunities for serious dialogue or debate between adherents of each are sadly lacking. There is, in other words, an impoverishment of meaning which makes the debate between universal and moderate inclusionists polarised, repetitive and barren. I now need to substantiate this claim.

The philosopher Wittgenstein wrote:

Must I know when I understand a word? Don't I also sometimes imagine myself to understand a word... and then realise I did not understand it?

Wittgenstein wrote memorably that languages 'idles' when it is not connected to the machinery, as it were, of our everyday lives. To understand a word is to understand the difference it makes, the work it does, the role it plays in particular situations. If we deny that something is objectively 'real', are we saying that it is fake? Are we warning people not to pay too much money for it? If we can't answer this question, or identify some other practical difference between believing and disbelieving something, then we may not have a clue what we are talking about.

What does it mean to deny that differences between learners are 'real'? We should note, first, that the word 'real' rarely appears in this discussion without protective punctuation. It is not an everyday word, or at least not as it appears in this context, and this should arouse some suspicion. The philosopher J. L. Austin wrote: 
'Real' is an absolutely normal word, with nothing new-fangled or technical or highly specialised about it (1962, p. 62).

Austin was warning people about the dangers of what one might call airy-fairy thinking: thinking that relies on language that 'idles', in Wittgenstein's sense, because it is disconnected from everyday life. Austin and Wittgenstein were profoundly sceptical about metaphysics - they thought that much if not all of it was literally meaningless - and in this they may have gone too far. But they were right, in my view, to point out that the meaning of a term like 'real' is at the very least hard to pin down. To earn its keep, as it were, metaphysics requires difficult, sustained reflection. Inverted commas around words that give off a metaphysical smell are no substitute for thinking.

We need to ask what difference it makes whether one asserts or denies that differences between learners are objectively 'real'. The answer is surely this: it makes an ethical difference and has nothing whatsoever to do with metaphysics. We have touched on the ethical difference. We have seen that people deny that differences between learners are real because they want to protect some children from the stigma of abnormality. The problem, however, is that this suggests that other people do not want to protect children from the stigma of abnormality. This suggestion is provocative and, I believe, in most cases untrue. I have argued that all inclusionists are motivated by a desire to protect children from disrespectful practices and attitudes.

The appeal to metaphysics to support an ethical argument is misguided and also damaging. There is a logical difference between metaphysics and ethics, which I should like to express as follows. Metaphysics tolerates and sustains either-or thinking, whereas ethics is often corrupted by such thinking. Assuming for a moment that we understand the claim that differences between learners are objectively 'real', it then makes sense to offer people a choice: do you believe or disbelieve this? It is reasonable to suppose that a choice must be made, as a dealer in coins must decide whether a coin is genuine or counterfeit. The idea of paradigms reinforces this idea. You are either a positivist or a post-positivist. You cannot be both.

Nothing could be less true when we turn to ethics. The art of thinking well ethically, if I may put it like this, is precisely to avoid creating false and unnecessary disjunctions by thinking through the options imaginatively. Yes, children should be protected from the stigma of abnormality. No, children's needs should not be 
neglected. If children have needs which have traditionally earned them the stigma of abnormality, then we must acknowledge and try to meet these needs and also, as far as possible, protect them from the stigma of abnormality. The idea that we either protect them from stigma or address their needs properly is a huge assumption.

It is also dangerous because it sets up false polarities, creating an atmosphere in which productive dialogue and debate are impossible. Imaginative solutions which synthesise apparent alternatives are discouraged. The metaphysical denial that differences are real slides into an ethical denial that your difficulties are real, provoking responses like the following:

...there is a tendency within the social model of disability to deny the experience of our own bodies, insisting that physical differences and restrictions are entirely socially created. While environmental barriers and social attitudes are a crucial part of our experience to disability — and do indeed disable us - to suggest that this is all there is to it is to deny the personal experience of physical or intellectual restrictions... (quoted Oliver, 1998)

This is a disabled person asserting: the restrictions of my body are real. One can understand why someone might be tempted to say this, and why the parents of children with disabilities are often desperately frustrated because their voices are not heard. The post-positivist paradigm denies such parents a voice by interpreting their appeals as an expression of erroneous and outdated metaphysics. This leads to the extreme polarisation that we see in special education today, and the result, as Brahm Norwich has rightly said, is a policy impasse.

My concern about the role of the concept of reality in special education is captured in this passage by Iris Murdoch:

There is a two-way movement in philosophy, a movement towards the building of elaborate theories, and a move back again towards the consideration of some simple and obvious facts. McTaggart says that time is unreal, Moore replies that he has just had his breakfast. Both of these aspects of philosophy are necessary to it. $(1970$, p. 1)

I am concerned that special educators have become so bewitched by their theories and so intent on their theory-building that they forget (to turn Moore's remark around) that some children have not yet had their breakfast. By this I mean that what is forgotten is that some children are losing out on an education. 
This impression is confirmed if we look at a rather confusing editorial chapter in a book about special educational theory. Theorising Special Education (Clark, Dyson and Millward eds, 1998) grew out of a concern that "the state of theorising in special education was complex, not to say confused." What follows is a commentary on this theorising which is as confusing as the theorising itself. Theorists, it is said, work in an "intellectual ghetto" involved in endless re-cycling of attacks on the positivist paradigm. There is "internal fragmentation" in which commentators "divide themselves into camps engaged as much in critiquing each other's work as in developing provision for vulnerable children." All this sounds like philosophers who are bewitched by the idea that Time is unreal. We are told that such theorists are "not likely to be predominantly interested in empirical enquiry or in questions that demand empirical answers"; on the contrary, "set positions are rehearsed with no very clear means whereby founding assumptions can be problematised or changed."

From these remarks, it sounds as though theorising in special education is in a bad way indeed. Vulnerable children and their needs or pains or difficulties are apparently no longer on the agenda. These are empirical matters, in which special educators of this ilk are 'not predominantly interested'. Instead, they are interested in 'set positions' which are immune to criticism or enquiry.

It is puzzling, having read this, to come across the sentence: "None of this constitutes a criticism of work undertaken within this paradigm." In this sentence (and elsewhere) the editors distance themselves from their unease with the state of theorising which the book sets out to address. I see this as a serious and unresolved equivocation. I would argue that it permeates not only this book, but the entire debate as it is conducted from a universalist or post-positivist perspective.

\section{Conclusion}

I want to conclude with a few remarks about the ethical importance of the concept of reality in discussions about special education. I begin by quoting two universalists whose theoretical position is that all differences between people are socially constructed. The first, Mike Oliver, writes: 
This appears in the course of an argument to the effect that many disabled people's lives have been taken over by professionals and pseudo-professionals. The second passage is this, by Derrick Armstrong:

The rhetorical emphasis upon mainstream schools as the point of delivery for educational support [under New Labour] was hardly new. Given the continuing reliance upon special schools for the most disabled and troublesome pupils the reality did not represent such a radical departure from the past as it was claimed to be (2005, p. 3, my emphasis).

Both Oliver and Armstrong use the term 'reality' (without inverted commas) in the course of an argument to the effect that something of importance has been overlooked. Both are committed to the proposition that there is no such thing as 'reality' beyond our social constructions. My purpose here is not to make a cheap point. It is to argue that the denigration of reality which permeates universalism is not only pseudo-metaphysical but unsustainable. Reality is not a super-realm to which our statements correspond or fail to correspond. Reality is what we point to when we are engaged in a debate with someone who, we feel, fails to see things clearly. We draw attention to reality in the course of an argument. We talk about reality when we try to be truthful or get something right. The concept of reality serves a purpose when we try to engage with each other and with the circumstances or situations in which we find ourselves. Raimond Gaita expresses this well:

Ethical understanding is often coming to see sense where we had not seen it before, or coming to see depth where we had not seen it before. It is seldom learning something completely new (there are no Nobel-prize winning discoveries in ethics) and it is seldom seeing that there is, after all, a valid argument to support positions we had previously judged to be dubious. It is often seeing what someone has made of something that we had often heard before. (2004, p. 281)

The term 'reality' is not used in this passage, but it seems to me that it is implied. The concept of reality plays a crucial role in enlightened and, I would say, respectful dialogue. We use the word 'reality' quite literally in the hope of enlightening people, bringing them to share our view. The use of this word, far from expressing a dogmatic or deluded notion of absolute truth, may carry a supposition that the other person is willing to respect one's view, take it seriously, consider re-thinking her position. The freedom to say 'the reality is this, not that', as Oliver and Armstrong do 
unwittingly, is essential for fruitful dialogue. It takes us beyond the stilted, consensual thinking that plagues so much sociology, in which motives and assumptions are ascribed to large numbers of people as though there is no possibility of variation.

It is essential that special educators hear individual voices, and attend to the realities to which they draw attention. There are many disabled voices, not just one, and many attitudes towards disabled people, not merely a prevailing attitude which issues from an abstraction called society. The term 'reality' plays a crucial role in a respectful dialogue between individuals, and this is what special education frequently lacks. Indeed one could say that what is needed is a truly inclusive dialogue, in which differences between disputants are heard and treated with respect. There is something deeply paradoxical about a debate which aims to secure respect for all children, conducted (as I believe it often is) without respect.

In this paper I have called for a substantial improvement in the quality of special educational debate. There is a backlash against inclusion-not against its fundamental values, but against its insistence on unconditional universality. This needs to be taken seriously, for nothing less is at stake than the decent, i.e. nonhumiliating, treatment of some children. Children who cannot flourish in inclusive mainstream schools are no doubt a small minority; but their existence has been highlighted in all sorts of ways in the last few years, and it needs to be acknowledged by all participants in the debate. The following is no doubt true:

...we should focus individualised special needs strategies only on the very small minority of children who genuinely need provision that is 'additional to or different from' what an enhanced mainstream can provide on a group basis (Dyson and Slee, 2001).

I have argued that failure to address the needs of a 'very small minority' means failure to accord respect to all, in favour of the contested and puzzling value of inclusion for all.

\section{References}

Ainscow, Mel (1998), 'Would it work in theory? Arguments for practitioner research and theorising in the special needs field', in Clark, C, Dyson, A, and Millward, A (1998), Theorising Special Education (London and New York: Routledge) 
Armstrong, Derrick (2005), 'Reinventing "inclusion": New Labour and the cultural politics of special education', Oxford Review of Education, vol. 31 (1)

Austin, J. L. (1962), Sense and Sensibilia (Oxford \University Press)

Barton, Len (1993), 'Labels, markets and inclusive education', in Special Educational Needs after Warnock, Visser, J and Upton, G, eds, (London: David Fulton)

Burne, J (2005), 'Say it loud, autistic and proud', Observer newspaper (13.11.2005)

Centre for Studies in Inclusive Education (CSIE) (undated), 'Reasons against segregated schooling', http://inclusion.uwe.ac.uk/csie/reasonsagstsegschooling.pdf

Cigman, R (2001), 'Self-esteem and the confidence to fail', Journal of Philosophy of Education, vol. 35 (4)

Cigman, R (2004), 'Situated self-esteem', Journal of Philosophy of Education, vol. 38 (1)

Cigman, R (2007), Editorial Introduction, Included or Excluded? The challenge of the mainstream for some SEN children, Cigman, R, ed, (Routledge)

Clark, C, Dyson, A, and Millward, A (1998), Theorising Special Education (London and New York: Routledge)

Dyson, Alan and Slee, Roger, Special Needs education from Warnock to Salamanca: the Triumph of Liberalism? (2001), in Education, Reform and the State - Twenty Five Years of Politics, Policy and Practice, Furlong, J and Phillips R eds, (RoutledgeFalmer)

Gaita, Raimond (2004), Good and Evil (Routledge)

Kant, Immanuel, Groundwork of the Metaphysics of Morals, passim, but especially chapter 1 (many editions)

Oliver, Mike (1996), Understanding Disability: from theory to practice (Palgrave)

Margalit, Avishai (1996), The Decent Society (Harvard University Press)

Moore, Charlotte (2007), 'Speaking as a parent: thoughts about educational inclusion for autistic children', in Included or Excluded? The challenge of the mainstream for some SEN children, Cigman, R, ed, (Routledge)

Murdoch, Iris (1970), The Sovereignty of Good (London: Routledge and Kegan Paul)

Pirrie, A and Head, G (2007), 'Martians in the Playground: researching special educational needs', Oxford Review of Education, vol. 33 (1) 
Rogers, C (2007a), Parenting and Inclusive education: discovering difference, experiencing difficulty (PalgraveMacmillan)

Rogers, Chrissie (2007b), 'Experiencing an "inclusive" education: parents and their children with "special educational needs", British Journal of Sociology of Education, vol. $28(1)$

Sainsbury, C (2000), Martian in the playground: understanding the schoolchild with Asperger's syndrome, (Sage publications)

Sinclair, Jim (1998a), 'Concerns about inclusion from within the disability community’ http://web.syr.edu/ jisincla/inclusion.htm

Sinclair, Jim (1998b), 'Why I dislike person first language' http://web.syr.edu/ jisincla/person_first.htm

UNESCO (1994), The UNESCO Salamanca Statement and Framework for Action on Special Educational Needs Education (Paris: UNESCO)

Warnock, Mary (2005), Special Educational Needs: a new look (London: Philosophy of Education Society of Great Britain)

Wittgenstein, L (1968), Philosophical Investigations (Oxford: Basil Blackwell) 